\title{
COMBINED ANALYTICAL AND EXPERIMENTAL INVESTIGATIONS FOR LWR CONTAINMENT PHENOMENA
}

\author{
HANS-JOSEF ALLELEIN ${ }^{\mathrm{a}, \mathrm{b},{ }^{*}}$ ERNST-ARNDT REINECKE ${ }^{\mathrm{b}}$, ALEXANDER BELT $^{\mathrm{a}}$, PHILIPP BROXTERMANN ${ }^{a}$, \\ and STEPHAN KELM ${ }^{\mathrm{b}}$ \\ ${ }^{a}$ Institute of Reactor Safety and Reactor Technology LRST, RWTH Aachen University \\ 52064 Aachen, Germany \\ ${ }^{\mathrm{b}}$ Institute of Energy and Climate Research IEK-6 \\ Forschungszentrum Jülich GmbH, 52425 Jülich, Germany \\ *Corresponding author. E-mail : allelein@LRST.rwth-aachen.de
}

Received March 21, 2012

Main focus of the combined nuclear research activities at Aachen University (RWTH) and the Research Center Jülich (JÜLICH) is the experimental and analytical investigation of containment phenomena and processes. We are deeply convinced that reliable simulations for operation, design basis and beyond-design basis accidents of nuclear power plants need the application of so-called lumped-parameter (LP) based codes as well as computational fluid dynamics (CFD) codes in an indispensable manner. The LP code being used at our institutions is the GRS code COCOSYS and the CFD tool is ANSYS CFX mostly used in German nuclear research. Both codes are applied for safety analyses especially of beyond design accidents.

Focal point of the work is containment thermal-hydraulics, but source term relevant investigations for aerosol and iodine behavior are performed as well. To increase the capability of COCOSYS and CFX detailed models for specific features, e.g. recombiner behavior including chimney effect, building condenser, and wall condensation are developed and validated against facilities at different scales. The close connection between analytical and experimental activities is notable and identifying feature of the RWTH/JÜLICH activities.

KEYWORDS : Severe Accident, Beyond-Design Basis Accident, Containment Phenomena, COCOSYS, CFX, Passive Heat Removal

\section{INTRODUCTION}

The containment of large pressurized water reactors (PWRs) has a volume of up to $70,000 \mathrm{~m}^{3}$ and is subdivided into different compartments, which house the components of the reactor cooling system and auxiliary systems. During the course of a design and beyond design-basis accident, large quantities of steam and hydrogen are released from the break location into the containment within a short time. Detailed knowledge of the spatial distribution of gases and the atmospheric conditions is essential, e.g. for the design of safety systems and accident management, and therefore the goal of accident analysis [1]. In particular, these results provide essential information for the following analyses of possible hydrogen combustion loads and the radiological source term (Fig. 1).

The Containment Code System COCOSYS developed by GRS [2,3] analyzes the course of an accident in the containment, the plant performances, and the possible consequences and countermeasures in case of an accident. The COCOSYS approach itself is 0-dimensional but due to the representation of the configuration, 3-dimensional flows can be simulated. COCOSYS is based on mechanistic models that enable to reproduce important phenomena in the containment and to calculate plant status during operation, design basis accidents as well as during a severe accident. It is also possible to evaluate accident management measures, to quantify the safety margins, to assess mitigating measures, to evaluate the safety of new plant concepts, and to identify possible deficits in plant safety with COCOSYS. The program consists of three main modules:

- Thermal hydraulic module (THY)

- Aerosol-fission-product module (AFP)

- Molten core concrete interaction module (MCCI)

For more detailed analyses and assessments, Computational Fluid Dynamics (CFD) are used more widely in nuclear reactor safety issues in order to describe three-dimensional flow and transport processes [4,5]. Although LP codes maintain an important role in the integral investigation of accident scenarios, there are a number of unresolved issues which require the detailed knowledge of 3D and transient flow and transport processes.

By the way of an example, the analysis of the efficiency and sufficient capacity of passive safety systems, like Passive Auto-Catalytic Recombiners (PARs) or containment 


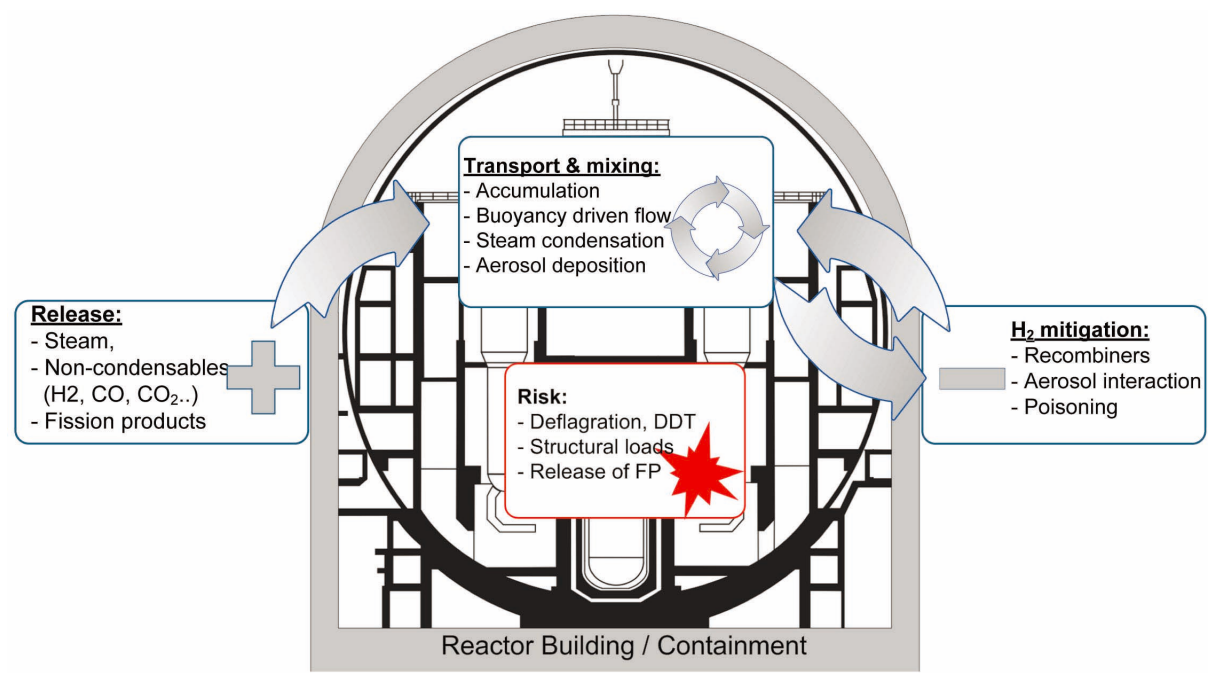

Fig. 1. Containment Phenomena and Processes with Regard to Hydrogen Combustion Loads and Radiological Source Term

condensers (in modern BWR designs), needs a reliable prediction of the buoyancy-driven flows and mixing phenomena. Besides the investigation of basic thermal hydraulic transport processes also the risk of ignitions and subsequent combustion of the local hydrogen/air mixture is subject of accident analyses. A precise prediction of the local hydrogen concentrations and atmospheric conditions is a fundamental requirement in order to estimate combustion loads on the containment structures.

A CFD simulation of the thermal-hydraulic processes in the containment must include besides all occurring physical phenomena, e.g. turbulent heat and mass transfer, condensation, and buoyancy driven flows, also models for relevant containment systems like e.g. burst-discs, doors, sumps, and PARs. The latter component models are not available in today's commercial (and industrially applied) CFD code packages. Furthermore, the physical models, e.g. turbulence models, have been developed for different fields of application like aerodynamics. Their range of application cannot be extended to containment-typical flows without further development and validation.

In the frame of the ISP-47 on containment thermal hydraulics [6], the phenomena wall condensation, buoyancydriven flows and stratifications as well as their interactions have been investigated in the experimental test facilities THAI (Thermal-hydraulics, Hydrogen, Aerosols, Iodine, Becker Technologies, Eschborn, Germany), MISTRA (MItigation and STRAtification, CEA Saclay, France) und TOSQAN (IRSN, France). The main conclusion of the benchmark was that there is the need to enhance CFD models for the prediction of buoyancy-driven flows and stratifications, condensation processes, and turbulent mixing.

In the meantime, during various German (e.g. THAI I-IV [7]) and international projects (e.g. OECD/NEA
SETH-2 [8] and THAI [9], or EU-SARNET [10] and EU-ERCOSAM [11]), an extensive database, including data with high spatial resolution, was established. This data base is well-suited for development and validation of CFD models which are able to describe flow and transport processes, especially the hydrogen distribution, in a containment during an accident.

RWTH and JÜLICH contribute to national and international efforts with the development and validation of models, especially for the prediction of physical phenomena and for the simulation of the operational behavior of passive safety devices. By this, the scientific activities touch a vast variety of phenomena such as buoyancy-driven flows, wall condensation, heterogeneous catalysis, or iodine chemistry. Developed models are provided for and implemented in LP codes as well as in CFD approaches.

\section{MODELING OF CONTAINMENT CONDENSERS}

Several next-generation Light Water Reactors (LWR) will feature innovative systems for passive heat removal during accidents from both the primary circuit and the containment. The passivity is based on natural driving forces only, such as gravity and natural circulation [12,13]. Containment Condensers (CCs) have been proposed for PWR containment cooling, already. In the EU project INCON [14], a horizontal-finned tube CC and in [15] a vertical bare tube $\mathrm{CC}$ have been examined. $\mathrm{CCs}$ are considered in the design of the Russian AES-2006 also known as MIR-1200 [16] reactor concept. At RWTH, the new containment Condenser Module (COMO) is currently under development. The module evaluates the contribution of CCs to passive containment cooling. 


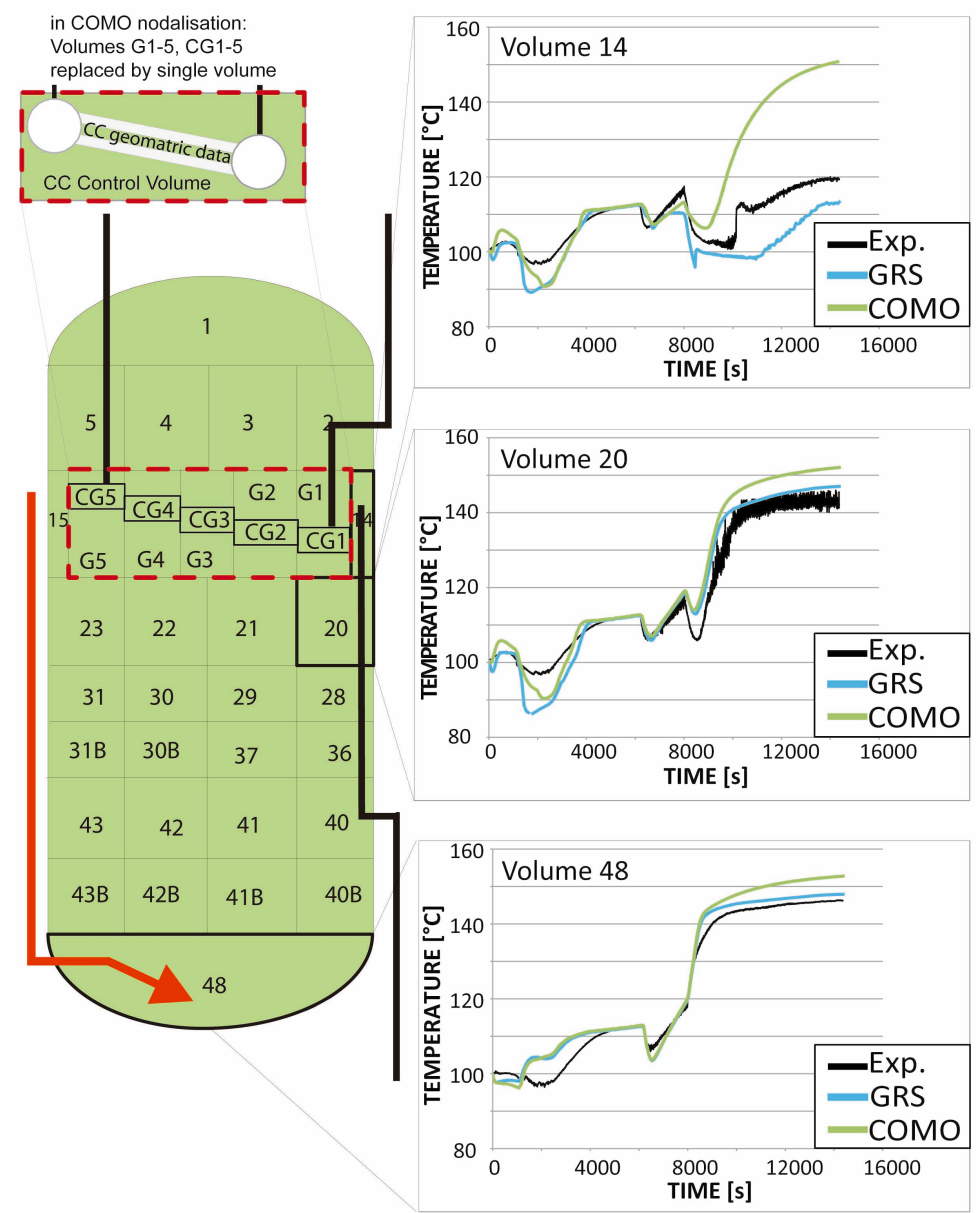

Fig. 2. Temperature Evolution of the CC Containing Dry-well Vessel in PANDA BC4.

COMO is implemented as a routine within COCOSYS' thermal-hydraulic main module THY and is structured in different subroutines, representing the different processes important for $\mathrm{CC}$ behavior description. The module is able to calculate the heat transfer to finned and bare tubes, the heating of the cooling water within the tubes from inflow to outflow, and the buoyancy driven natural circulation in a transient form. This is done by solving corresponding unsteady conservation equations which are integrated in COCOSYS by the provided integration routine.

The ability of COCOSYS to simulate the thermalhydraulics within vessels cooled by means of passive systems with the integrated COMO is demonstrated by modeling the PANDA facility and calculating experiment $\mathrm{BC} 4$ [17]. In this experiment, a CC was installed in one of the dry-well vessels (DW). The test vessel representing the reactor pressure vessel (RPV) is filled with water which is heated up during the experiment. When the valve of the RPV opens, steam flows into the sump underneath the CC and into the upper part of the other DW vessel. Thus, steam is emerging from the sump and is then condensed on the $\mathrm{CC}$ tubes. The condensate falls back into the pool. In order to simulate core degradation and hydrogen release, helium is injected at the top of the RPV. The purpose has been to figure out the behavior of the $\mathrm{CC}$ in presence of non-condensable gases. The connection to the wet-well via vent pipe for non-condensable gas removal, which was proposed in the SWR1000 concept, has been considered, too. To inhibit the $\mathrm{CC}$ to cool the atmosphere during heat up, the water level in the pool does not cover the upper feed line. The pool is filled up in the first phase of the experiment. During the experiment, the cooling water passively circulates through the $\mathrm{CC}$ tubes due to heating.

In Fig. 2, the schematics of the facility and the nodalisation prepared by GRS are presented $[18,19]$. For the calculation with COMO it has been changed, however, in respect to the new possibilities to insert a $\mathrm{CC}$ in a single control volume. Comparing the nodalisation of the $\mathrm{CC}$, it is obvious that in the former GRS calculation the $\mathrm{CC}$ was nodalized with 10 control volumes ( 5 volumes for tube segments and 5 for the adjacent atmospheric volumes) with associated junctions and thermal conductors. Whereas 
when COMO is applied to the simulation, only one control volume has to be defined with the associated CC described by the actual geometry.

The comparison of experimental results and the calculation are in good agreement, at least up to $8000 \mathrm{~s}$ as can be observed in Fig. 2. The deviation of temperature evolution at the level of the vent pipe and CC after that point is explicable by the arising boiling conditions within the tubes. This has not been considered until now by COMO and thus leads to considerable difference between measured and calculated cooling power.

The introduction of COMO is a promising step forward concerning CC simulation with the lumped parameter code COCOSYS. COMO features several aspects for CC simulation that have not been available up to now. Especially the ability to simulate a CC with passively induced fluid flow, which is a new possibility to calculate transient conditions. Furthermore, the application of a CC to a multicompartment simulation is facilitated by far, because of the simple input requirements. This eliminates error sources induced by the user in an otherwise complex input, while delivering more reliable results as in the past. Current work includes the implementation of boiling conditions and two phase flow within the condenser to account for a much larger heat transfer due to boiling. Keeping in mind the many adjustments already required in a pure COCOSYS input to meet PANDA BC4 experimental results, less uncertainties are likely to affect eventual reactor containment simulation by applying COCOSYS with COMO.

In the course of this work the impact of CCs on the containment atmosphere of a large PWR $\left(43,000 \mathrm{~m}^{3}\right.$ free dome volume) has been examined during accident conditions. By doing this, basic information has been gained about the behavior of CCs in large containments with large free volumes and the impact on the thermal-hydraulics during the accident.

\section{BUOYANCY-DRIVEN FLOWS AND STRATIFICATION}

The transport processes in the containment are induced by different mechanisms. On the one hand, buoyant forces due to e.g. condensation or concentration differences can lead to an establishment of an atmospheric stratification and thus a local stagnation of the flow which might affect safety systems or lead to a dangerous accumulation of hydrogen. On the other hand these stratifications can be remobilized by means of momentum or buoyancy driven flows like they are induced by ventilation, coolers or the hot exhaust gas plume of a PAR. Thus the simulation of these processes is a central task in the prediction of containment thermal hydraulics.

In order to distinguish between possible experimental side effects and needs for model enhancement, validation is not performed based on a single experimental setup, but moreover by a comparative evaluation of similar (in terms of characteristic dimensionless numbers) experiments in different experimental facilities. Fig. 3 demonstrates this approach applied to the erosion of a light gas layer by means of a vertical momentum jet.

In the context of buoyant flows, condensation plays a major driving role in containment thermal hydraulics. Wall condensation on the cold structures of the containment results on the one hand in strong density gradients, on the other hand allows high heat transfer rates. Wall condensation rates in the presence of non-condensable gases is limited by mass transport to the walls $[20,21]$, i.e. all effects related to the film can be neglected and condensation can be modeled as a single phase process. This modeling approach allows on the one hand reducing computational effort, but induces on the other hand the duty to resolve the transport processes in the condensing boundary layer

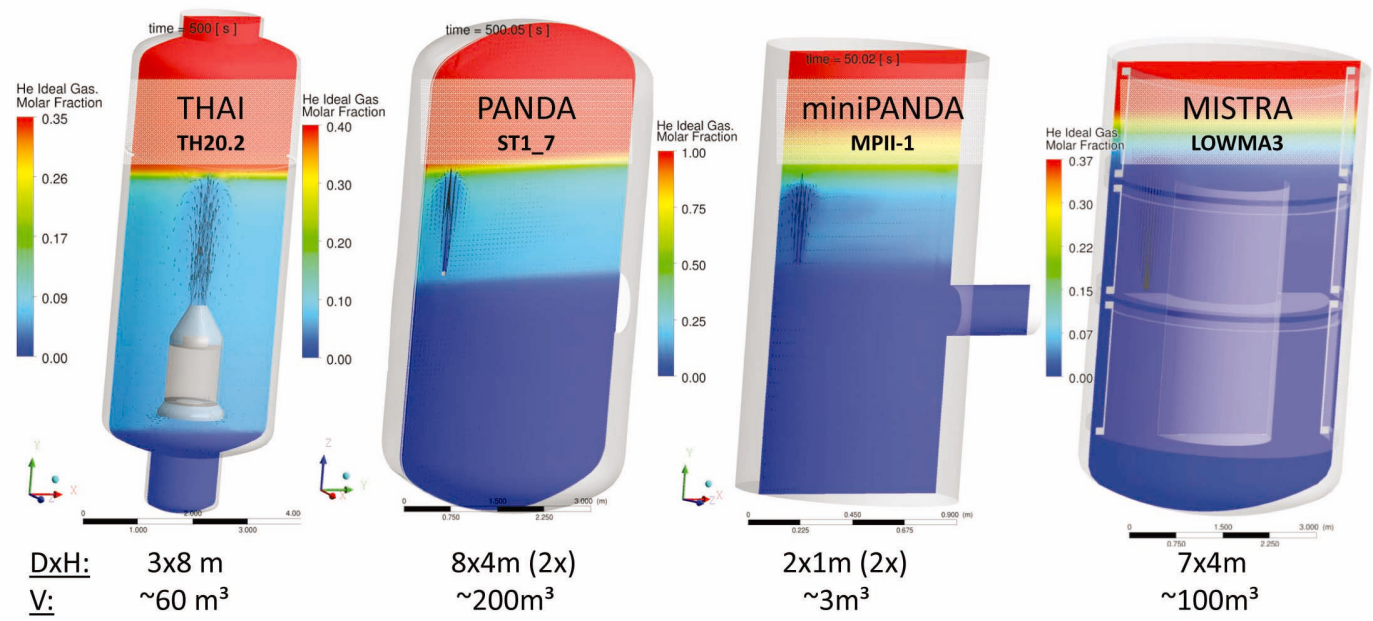

Fig. 3. Example of a Comparative Evaluation: Erosion of a Light Gas Layer by Means of a Momentum Jet for Similar Characteristic Froude Numbers in four Different Facilities. 
in an appropriate manner. In order to avoid a detailed grid resolution of the near wall gradients so-called "standard wall functions" are widely applied in CFD-codes. These predefined wall normal profiles can however lead to a significant error when applied to condensing boundary layers as condensation induces strong buoyant forces and leads to a thinning of the boundary layer [22].

In order to investigate the transport processes inside the condensing boundary layer, the SETCOM (Separate Effect Tests for Condensation Modeling) facility is currently under construction at JÜLICH. This facility will be equipped with high resolution optical measurement techniques and will for the first time provide measurements of wall normal gradients of the relevant variables, i.e. velocity, species concentration and temperature. This database will be applied for a further development and assessment of enhanced wall functions for condensing boundary layers.

This goal is a challenge for the design of the test facility. On the one hand individual influences on the heat and mass transfer have to be quantified separately and on the other hand measured with high detail but without disturbing the transport processes inside the boundary layer. For the latter reason, non-intrusive, optical measurement is applied which ensures an 'undisturbed' development of the boundary layer. The following individual effects on the local condensation rates will be investigated within the measurement campaigns:

1. Effect of temperature gradient between wall and flow

2. Effect of steam gradient between wall and flow

3. Impact of non-condensable gases $\left(\mathrm{He}, \mathrm{CO}, \mathrm{CO}_{2}\right)$

4. Inclination of the wall
5. Separation of velocity and temperature boundary layer

Within each test series, every individual effect will be investigated for different flow regimes:

1. Natural convection

2. Mixed convection

\section{Forced convection}

Besides the gathering of 'CFD-grade' condensation data the main challenge is the realization of 'CFD-grade' boundary conditions, i.e. boundary conditions which can be transferred consistently and without any further assumptions or simplifications from the experiment to the numerical model.

For this reason each component of the facility will be designed, characterized and optimized in preliminary tests. The overall flow scheme of the SETCOM facility is shown in Fig. 4. It consists basically of three main parts:

1. Test section

2. Primary loop

3. Secondary loop

The test section is a rectangular flow channel which provides basically a $2 \mathrm{D}$ flow field. The dimension of the test channel cross section was chosen so that edge effects of the side walls on the boundary layer formation in the center of the flat plate are negligible. Its length of $6 \mathrm{~m}$ allows investigating fully developed flows. One wall of the test section is cooled by means of the secondary cooling system while the other three walls are optionally heated in order to realize an adiabatic boundary condition and avoid unintended condensation. The side walls contain (also heated) optical windows for the non-intrusive measurements.

\begin{tabular}{l|l} 
I & Test section \\
\hline II & Primary loop $\left[+216 \mathrm{~kW}\left(-\Delta \mathrm{p}-\mathrm{Q}_{\text {loss }}\right)\right]$ \\
\hline III & Secondary loop $(-200 \mathrm{~kW})$
\end{tabular}

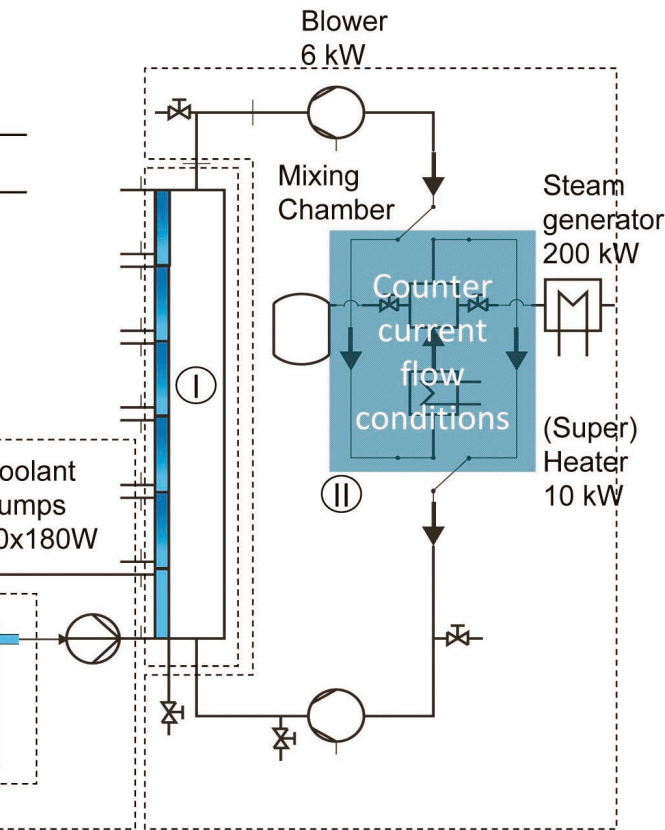

Fig. 4. Flow Chart SETCOM Facility 
The test section is integrated into a "closed" loop (primary loop), in which a gas mixture is circulated by a blower with a defined flow velocity. Over the system boundary of the primary loop steam and condensate is added or removed. Depending on the steam feed rates of the steam generator, the relative humidity of the gas mixture is varied. The performance of the steam generator $(200 \mathrm{~kW})$ has been estimated from the maximum condensation rates. Furthermore, heat is exchanged over the primary loop boundary by (super) heater. As a result of the (super) heater the temperature level of the gas mixture is varied.

The dry gas composition is controlled by specific feeding rates and monitored with the help of sensors. In addition to air, helium, $\mathrm{CO}$ and $\mathrm{CO}_{2}$ are considered as severe accident relevant non condensable gases. The main atmospheric parameters where chosen as reported by de la Rosa et al. [20]. Only investigations with hydrogen and overpressure will not be considered for safety reasons. Based on proven properties with similar safety issues, hydrogen is replaced by helium. In order to investigate the effect of buoyant forces the test section is mounted on a rotatable frame which allows investigating inclination angles of $0^{\circ}-90^{\circ}$ (Fig. 5).

In this figure, the access of the laser into the test section is indicated. The optical measurement system consists of a simultaneous Raman and Rayleigh scattering spectroscopy allowing the measurement of the species and temperature gradients, combined with a PIV measurement system which provides the velocity field (Fig. 6). The condensing wall is equipped with paired thermocouples (PT-100) for heat flux and temperature measurement with a spatial resolution of $20 \mathrm{~cm}$. All bulk properties are monitored and controlled by means of heat conductivity sensors (helium concentration), hot wire and vane wheel anemometer (flow velocity), humidity sensors (dry bulb/wet bulb), and thermocouples (bulk temperature).

The secondary cooling system allows the precise definition of a nearly uniform wall temperature and heat transfer coefficient by means of 120 counter current cooling tubes fed by 20 individual pumps.

SETCOM operation is scheduled to begin in October 2012 and will for the first time provide an in-sight into the transport processes of condensing boundary layers. CFD-grade data and boundary conditions will be applied for the development of dedicated near-wall models for wall condensation.

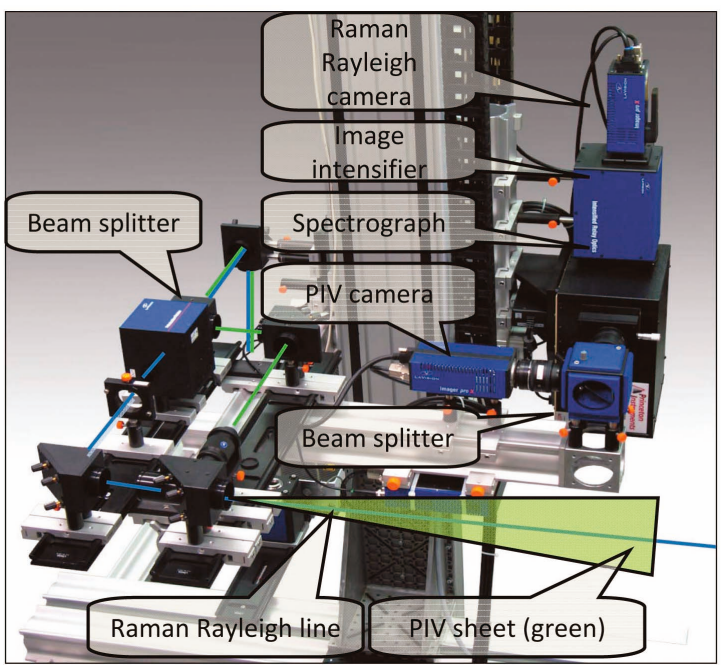

Fig. 6. High Resolution Optical Measurement

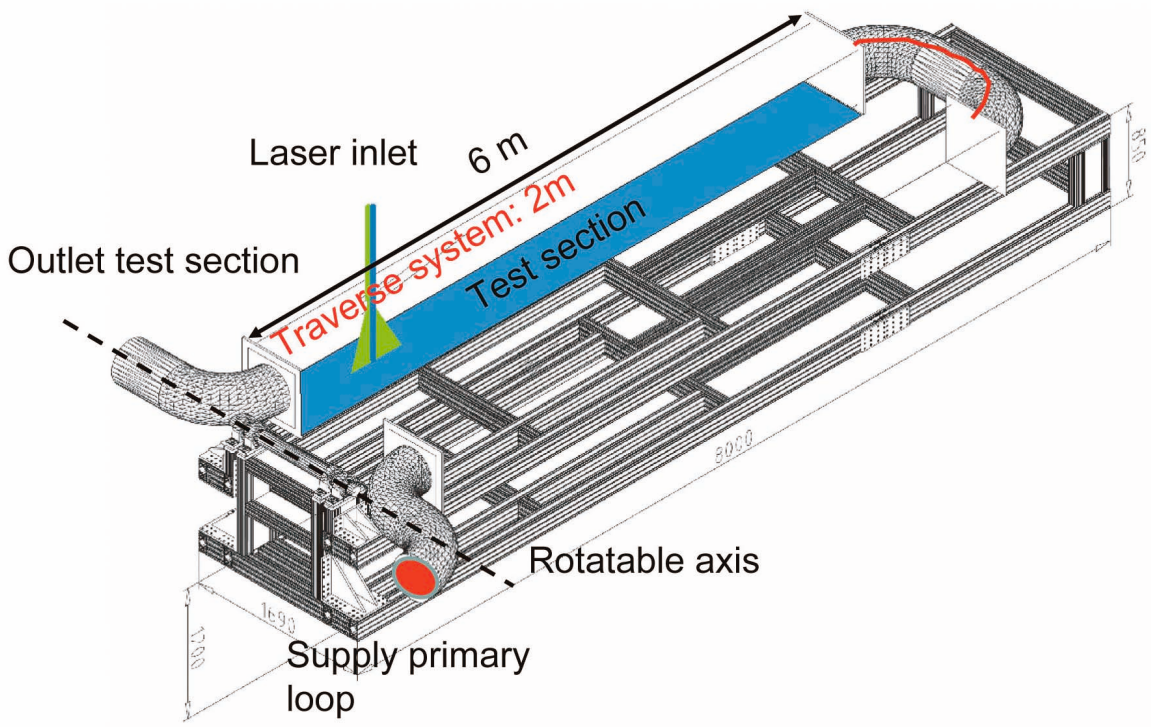

Fig. 5. Rotatable Mounted Test Section 


\section{OPERATIONAL BEHAVIOR OF PASSIVE AUTO- CATALYTIC HYDROGEN RECOMBINERS}

Passive auto-catalytic recombiners (PARs) are installed inside the containments of nuclear power plants in many countries in order to remove hydrogen that may be released during a loss-of-coolant accident and to avoid possible threats related to hydrogen combustion [23]. Besides the removal of hydrogen, PARs contribute to the containment thermal hydraulics by inducing heat and flow patterns promoting atmosphere mixing. Containment thermal hydraulics may also affect PAR operation, e.g. if startup is delayed due to a downward flow at the cold containment walls. Steam condensation on the catalyst sheets may cause start-up delay, while aerosols may impact start-up and operation as well.

PAR operation has a significant impact on flow and transport processes inside the containment. On the one hand the composition of the atmosphere is changed due to the catalytic reaction, on the other hand the reaction acts as a heat source and induces buoyancy driven flow. The resulting hot exhaust plume of a PAR can either induce a thermal stratification or mixing processes depending on the local conditions [24]. In return, the thermal hydraulic transport processes give the important boundary conditions for PAR operation, i.e. local concentrations of reactants or conditions for the start-up of the catalytic reaction. Thus, the strong interaction between PAR and containment atmosphere needs to be modeled carefully. For this purpose, the detailed mechanistic model REKO-DIREKT, has been coupled to the CFD code ANSYS-CFX [25,26]. This allows on the one hand having a detailed representation of all relevant phenomena related to PAR operation, but on the other hand to avoid too high grid requirements in the CFD simulation. Fig. 7 shows a typical simulation result for a PAR test in the German THAI facility.

The validation strategy includes a separate validation of the thermal-hydraulic model by means of OECD/NEA SETH-2 tests in the Swiss PANDA facility [8,24], where the PAR is represented by means of a heat source, and coupled validation based on REKO-4 experiments performed at JÜLICH, and integral PAR tests performed in the frame of the OECD/NEA THAI project in the German THAI facility [9].

In order to study phenomena related to PARs, several facilities are in operation at different scales. The goal is to further enhance the reliability of numerical models describing the operational behavior of PARs under relevant conditions. The experiments serve at solving open issues related to PAR modeling [27] including

- PAR ignition

- CO recombination

- low-oxygen efficiency

- PAR-aerosol interaction

These facilities complement existing integral experimental programs which have been performed in the past (e.g. the French H2PAR and KALI experiments or the German BMC [23]), or which are still under operation (e.g. THAI
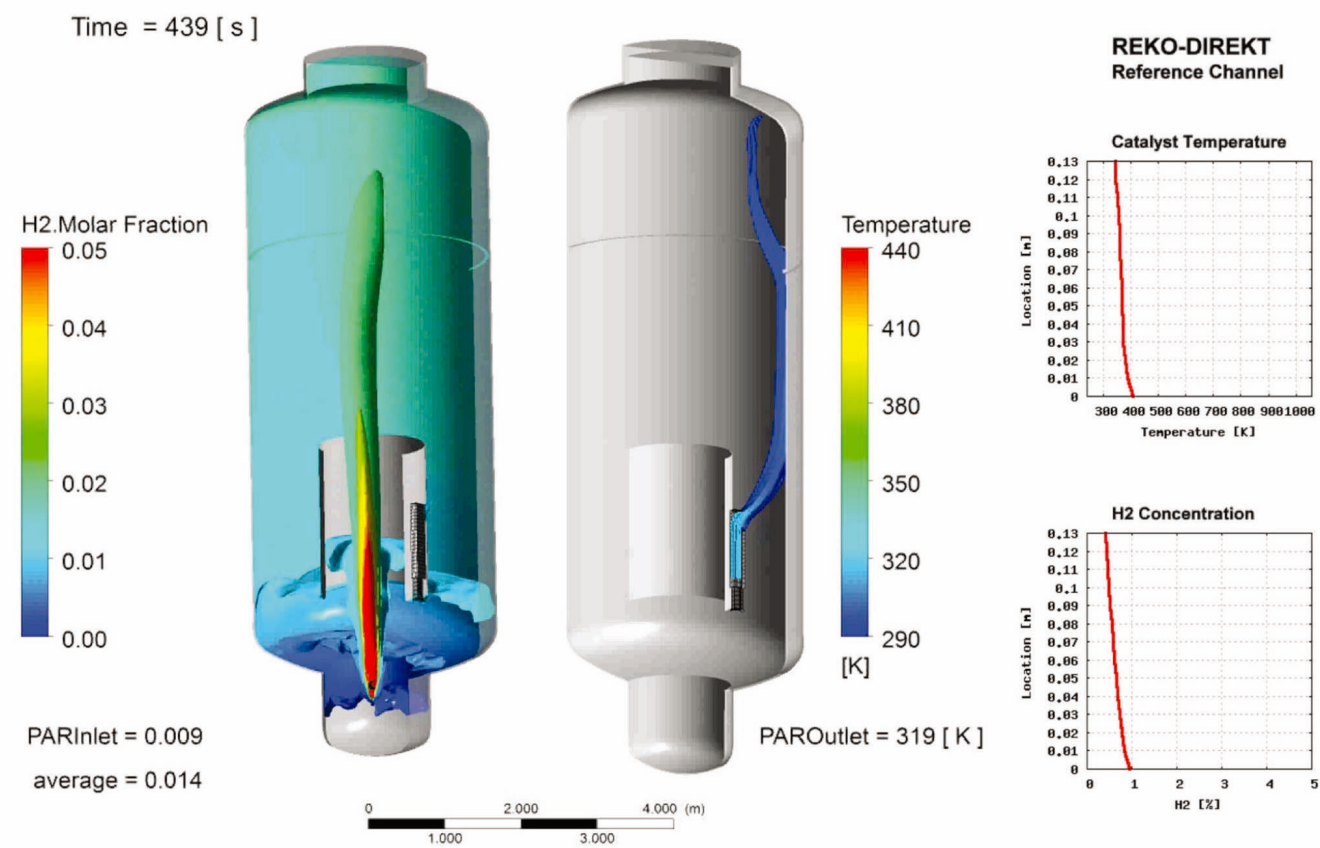

Fig. 7. Simulation of a THAI PAR Test: Hydrogen Distribution (Left), Temperature Distribution (Middle) and REKO-DIREKT Results (Right) 
[28]). Rather than studying the global PAR performance, e.g. the global conversion rate, these particular experiments aim at studying to understand the processes inside the PAR in order to provide a database for the validation of more detailed mechanistic PAR models.

Well defined conditions are needed to derive reaction kinetics and to be able to specifically vary boundary conditions. The REKO-3 facility represents a full scale section taken out of the recombiner catalyst section to be investigated under forced flow conditions [29]. This section consists of four catalyst sheets arranged inside a vertical flow channel (Fig. 8). The gas mixture which is fed into the flow channel consists of different components and is well defined by means of mass flow controllers, pre-heater and steam generator. Basic measurements include gas temperatures, catalyst temperatures at 10 positions per catalyst sheet, hydrogen and oxygen concentration at 14 positions along the sheets. Together with the known inlet conditions, these data enable the validation of the reaction kinetics model describing the hydrogen conversion [30].

The comprehensive REKO-3 database for validation of numerical PAR models includes experimental data on hydrogen conversion and catalyst temperatures for a wide range of boundary conditions. Table 1 gives an overview of the REKO-3 data base and the parameter field covered.

In order to study the interaction of the catalyst section with the chimney, the new facility REKO-4 has been under operation since 2010. REKO-4 consists of a $5.5 \mathrm{~m}^{3}$ vessel with a total of 35 flanges (Figure 9a). The facility may be operated at a pressure of up to 2.3 bar at $280^{\circ} \mathrm{C}$. Two special types of measurements are applied here. The local hydrogen concentration is measured in-situ by means of mini-katharometers in order to avoid the removal of gas from the vessel. The flow velocity field of the PAR inflow is measured by means of Particle Image Velocimetry (PIV) in order to avoid disturbing the inflow by measurement installations.

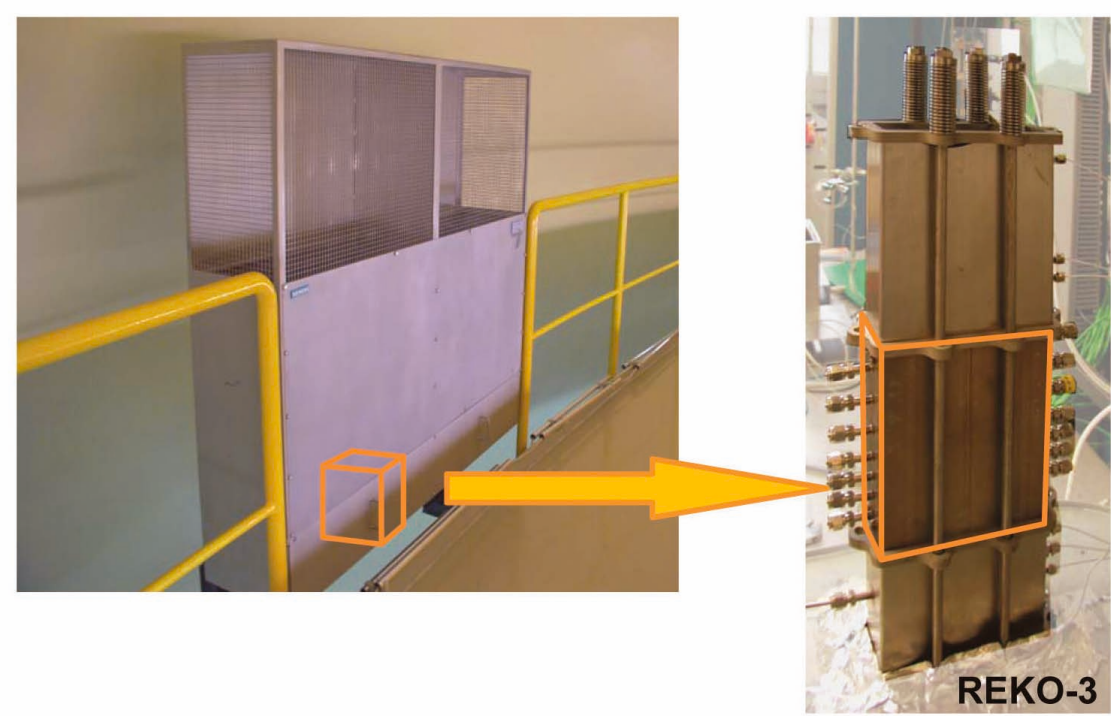

Fig. 8. REKO-3 Experiments for Reaction Kinetics Inside a PAR

Table 1. Parameters of the REKO-3 Database

\begin{tabular}{|c|c|c|c|c|c|c|c|c|}
\hline Requirements & \multicolumn{8}{|c|}{ Values } \\
\hline Flow velocity $(\mathrm{m} / \mathrm{s})$ & \multicolumn{2}{|c|}{0.25} & \multicolumn{2}{|c|}{0.50} & \multicolumn{2}{|c|}{0.80} & \multicolumn{2}{|c|}{1.00} \\
\hline Inlet gas temperature $\left({ }^{\circ} \mathrm{C}\right)$ & 20 & 110 & 20 & 110 & 20 & 110 & 20 & 110 \\
\hline Hydrogen concentration (vol.\%) & $1-7$ & $1-6$ & $1-7$ & $1-5$ & $1-7$ & $1-5$ & $1-7$ & \\
\hline Steam concentration (vol.\%) & & $0-60$ & & $0-20$ & & $0-20$ & & \\
\hline Oxygen concentration (vol.\%) & $1-21$ & & $1-21$ & & $1-21$ & & $1-21$ & \\
\hline
\end{tabular}


Inside the vessel, the PAR set-up is identical with the one used in the REKO-3 facility with an additional chimney on the top (Figure 9b). By this, a direct comparison of the measurement data from both facilities is possible.

The course of a typical experiment is given in Fig. 10. Hydrogen was injected over the time periods indicated by the yellow bars. The hydrogen concentration at the PAR inlet and outlet increases during the first injection phase until approx. 1,300 s when increasing catalyst temperatures (T_max and $\mathrm{T} \_\mathrm{min}$ ) indicate the starting of PAR operation. Repeated injections enable quasi-steady-state conditions when PIV measurements are performed. This procedure provides a correlation of inlet hydrogen concentration with hydrogen conversion, catalyst temperatures, and flow velocities.

\section{SOURCE TERM}

In case of a severe accident in a LWR, a large amount of radioactive fission products will be released from the reactor core into the containment. They represent a major

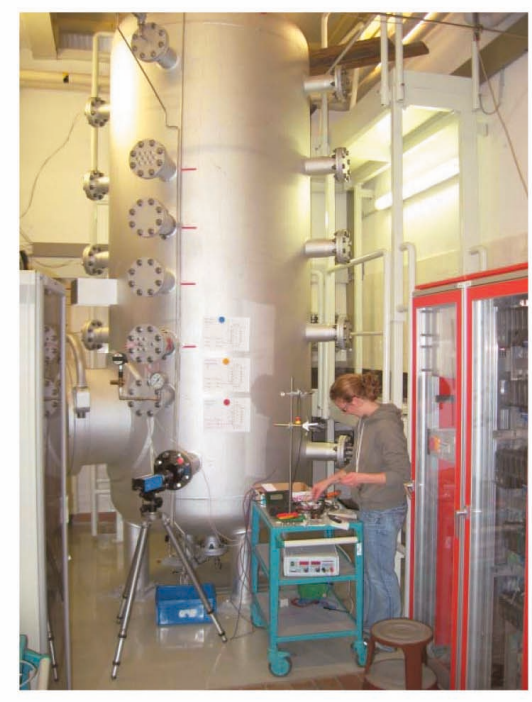

(a)

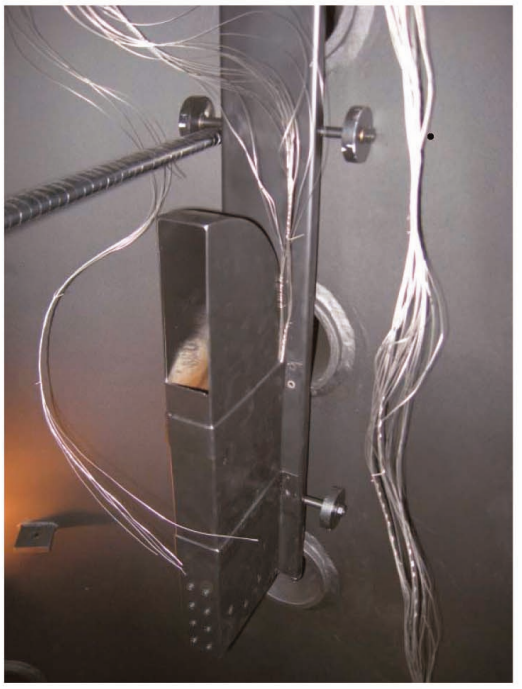

(b)

Fig. 9. REKO-4 Vessel (a), PAR Set-up used in REKO-4 (b)

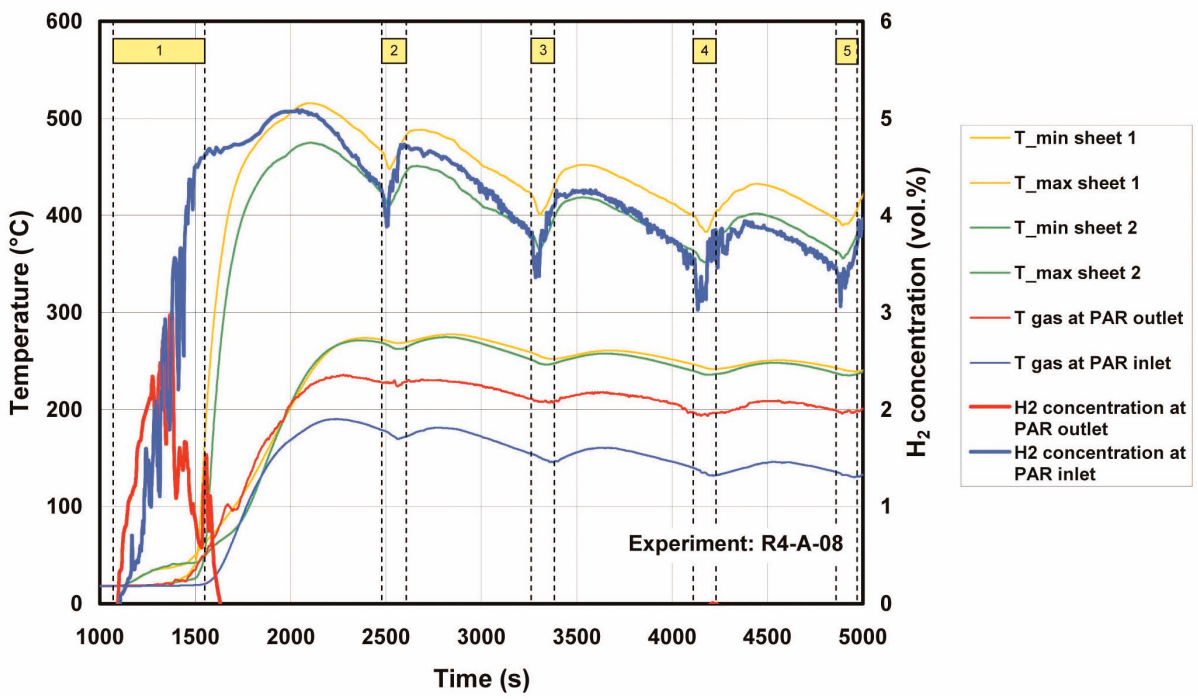

Fig. 10. Data from REKO-4 Experiment 


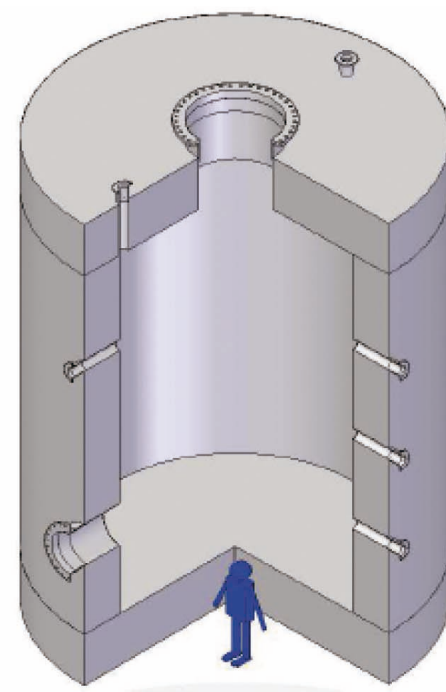

Concrete Cylinder with Steel Inliner

- Diameter $\sim 6 \mathrm{~m}$

- Height $\sim 8 \mathrm{~m}$

- Operating pressure up to $\sim 6$ bar

- Operating temperature up to $\sim 200^{\circ} \mathrm{C}$

Fig. 11. Technical Data of the Concrete Cylinder with Steel Inline Currently under Design in JÜLICH

radiological hazard to the environment. Knowledge of their transport, depletion, resuspension and especially for iodine the chemical behavior is therefore necessary in order to determine the radiological source term to the environment or to assess the impact of mitigation measures to prevent or minimize fission product releases [31].

At RWTH and JÜLICH, expertise in experimental aerosol science is currently built up. The activities with regard to the generation and characterization of different types of aerosols, such as core melt or fire aerosols focus especially on the investigation of multi-component aerosols.

For the experimental work, a test facility (INA) has been installed, which is specially designed for aerosol tests with high flow rates (e.g. for fire tests). The installed measurement techniques include an Aerodynamic Particle Sizer (APS), a Scanning Mobility Particle Sizer (SMPS) as well as an Electrical-Low-Pressure-Impactor (ELPI) for aerosol analysis. In addition to these aerosol measurement techniques, there are many additional analysis methods like Scanning Electron Microscopy (SEM) or $\mathrm{X}$-ray Fluorescence Analysis (XRF) available. Moreover it is possible to generate aerosols from powder and dilutions as well as from fire.

As a major new contribution, a new facility is currently under construction at JÜLICH. The concrete vessel with a diameter of approx. $6 \mathrm{~m}$ and a height of approx. $8 \mathrm{~m}$ will be equipped with a steel in-liner in order to provide wall boundary conditions and surfaces comparable to a LWR containment. Furthermore, the vessel will allow studies on filtered venting, which has gained increasing interest after the Fukushima accident. Fig. 11 gives an idea of the vessel currently under design and the basic design data.

Among the fission products being released in the course of a beyond design-basis accident, radioiodine (RI) plays an important role due to its high activity inventory, its volatility and its impact on the health of human beings and creatures. Under accident conditions, iodine is almost completely released from fuel. For the assessment of the source term into the environment, the airborne concentration should be known reliably. The iodine inventory in the containment atmosphere depends on numerous physicochemical processes such as deposition at and revolatilization from surfaces, reactions in gaseous and aqueous phases, and exchange of iodine between sump and atmosphere. The iodine concentration in the containment atmosphere depends strongly on the removal rates of the different iodine species being formed in the course of the accident. The radionuclides released into the containment lead to a high radiation level causing numerous reactions as well in the gaseous as in the water phases. An important aspect to be pointed out is the net effect of air/steam radiolysis products oxidizing gaseous $\mathrm{I} 2$ into iodine oxides (IOx). In the presence of other aerosols or droplets as typical for beyond design containment conditions, the reactive iodine oxides are expected to deposit onto their surfaces. This means that a volatile gaseous iodine species is converted into an aerosol iodine species [32].

In COCOSYS, the iodine behavior is simulated with the module Advanced Iodine Model (AIM). Based on experimental data from the international PHEBUS-FP, the Canadian (RTF), French (CAIMAN) and German (THAI) test series, the AIM was improved within the last decade. We are very interested in the effect of these different experimental results, resulting in modified or new detailed models in AIM. Consequently, we are using COCOSYS with AIM-3 for the assessment of the iodine source term to the environment. The scenario analyzed in a first step 
Table 2. Release Fractions of Relevant lodine Species (with Retention in the Venting Filters in Both Calculations)

\begin{tabular}{c|c|c}
\hline Species & Old results & New results \\
\hline $\mathrm{I}_{2}$ & $2 \mathrm{e}-4$ & $3 \mathrm{e}-5$ \\
\hline CsI & $1 \mathrm{e}-7$ & $9 \mathrm{e}-7$ \\
\hline IOx & $5 \mathrm{e}-4$ & $5 \mathrm{e}-7$ \\
\hline RI & $5 \mathrm{e}-6$ & $5 \mathrm{e}-4$ \\
\hline
\end{tabular}

is a medium break LOCA $\left(50 \mathrm{~cm}^{2}\right)$ with loss of the secondary heat sink in a German 1300 MW PWR. The containment is represented by a 20 -zone nodalization. Iodine chemistry is calculated simultaneously with the thermal-hydraulics and the aerosol phenomena. Specific attention is given to the four species $\mathrm{I}_{2}$, CsI, IOx and RI representing all organic iodine compounds.

At the end of the calculation, most of the iodine is in the sump (78\%) or deposited on the walls (21\%). Only about $1 \%$ is still airborne. In Table 2 , the results at $30 \mathrm{~h}$ are compared to old single-compartment calculations with MELCOR more than ten years ago [33]. It is evident that the knowledge improvement has led to major changes in the species to be released into the environment. Especially, the RI fraction released is now two orders of magnitude higher than before. This is of major importance with regard to comparatively poor retention of organic iodine in venting filters.

Another effect found in this analysis is that the highest temperature in the containment is higher than expected. The peak value is about $180^{\circ} \mathrm{C}$. However, most chemical reactions are only validated up to $130^{\circ} \mathrm{C}$. The investigation will be continued by simulating other accident scenarios and a comprehensive uncertainty study.

\section{CONCLUSIONS}

RWTH and JÜLICH contribute to national and international efforts with the development and validation of models, especially for the prediction of physical phenomena and for the simulation of the operational behavior of passive safety devices. By this, the scientific activities touch a variety of phenomena such as e.g. buoyancy-driven flows, wall condensation, or heterogeneous catalysis. Developed models are provided for and implemented in LP codes as well as in CFD approaches. The LP code being used is the GRS code COCOSYS and the CFD tool is ANSYS CFX.

With regard to COCOSYS model development and application, the introduction of the new module COMO is a promising step forward concerning Containment Cooler simulation and their contribution to containment thermal hydraulics. Based on the improved Advanced Iodine Model in COCOSYS, analysis of a LOCA scenario reveals significant differences compared to an earlier study, which is of importance with regard to comparatively poor retention of organic iodides in venting filters.

The close connection between analytical and experimental activities is notable and identifying feature of the RWTH/JÜLICH activities. In this context, existing facilities and facilities under construction serve to produce data for model development and validation for both LP and CFD codes in the area of wall condensation, passive auto-catalytic recombiners, and aerosol behavior. The main goal of the containment model improvements and validation is to increase the reliability of accident analysis in particular related to the prediction of the hydrogen distribution and efficiency of mitigation strategies during severe accident scenarios. Further objective of the common activities is the reduction of the still existing uncertain ties for radioactive source term predictions during the course of a beyond-design-basis-accident.

\section{REFERENCES}

[ 1 ] H. Karwat et al., "State-of-the-Art Report on Containment Thermal-hydraulics and Hydrogen Distribution", OECD/ NEA group of experts, CSNI/R(99)-16 (1999).

[2 ] H.-J. Allelein, S. Arndt, W. Klein-Heßling, S. Schwarz, C. Spengler, and G. Weber, "COCOSYS: Status of development and validation of the German containment code system", Nucl. Eng. .Des., vol. 238, pp. 872-889 (2008).

[3 ] W. Klein-Heßling, S. Arndt, and G. Weber, "COCOSYS V1.2 User's Manual”, GRS, Cologne (2000).

[4 ] B. Smith, "Assessment of CFD for nuclear reactor safety", Proc. OECD/NEA \& IAEA Workshop: Experiments and CFD code applications to nuclear reactor safety XCFD4NRS, NEA/CSNI/R(2009)12, Grenoble, France, Sept. 10-12, 2008.

[5] D. Bestion et al., "Recommendation on the use of CFD codes for nuclear reactor safety analysis", EVOL-ECORAD14, 5th EURATOM Framework Program (2004).

[6] H.-J. Allelein et al., "International Standard Problem ISP47 on Containment Thermal Hydraulics", Final Report, CSNI/R(2007)-10 (2007).

[7] T. Kanzleiter et al., "Experimental facility and program for the investigation of open questions on fission product behaviour in the containment - ThAI Phase II (ThAI = Thermal Hydraulics, Aerosols, Iodine)", Final Report, BMWi-1501272, Eschborn, Germany (2007).

[ 8 ] OECD/NEA SETH-2 Project, "Investigations of key issues for the simulation of thermal hydraulic conditions in water reactor containments", Final summary report (2005).

[9] OECD/NEA THAI Project, "Hydrogen and Fission Product Issues Relevant for Containment Safety Assessment under Severe Accident Conditions", Final report, NEA/CSNI/R (2010)3, (2010).

[10] J.-P. Van Dorsselaere, T. Albiol, B. Chaumont, T. Haste, C. Journeau, L. Meyer, B.R. Sehgal, B. Schwinges, D. Beraha, A. Annunziato, and R. Zeyen, "Sustainable integration of EU research in severe accident phenomenology and management", Nucl. Eng. Des., vol. 241, pp. 3451-3460 (2011). 
[11] D. Paladino, S. Guentay, M. Andreani, I. Tkatschenko, J. Brister, F. Dabbene, S. Kelm, H.-J. Allelein, D.C. Visser, S. Benz, T. Jordan, Z. Liang, J. Malet, A. Bentaib, A. Kiselev, T.Yudina, A. Filippov, A. Khizbullin, M., Kamnev, A. Zaytsev, A. Loukianov, and C. Boyd, "The EURATOMROSATOM ERCOSAM-SAMARA Projects on containment thermal-hydraulics of current and future LWRs for severe accident management, Proc. ICAPP '12, Chicago, USA, June 24-28, 2012.

[12] IAEA, "Status of advanced light water reactor designs", TECDOC-1391, IAEA, Vienna, Austria (2004).

[13] IAEA, "Passive Safety Systems and Natural Circulation in Water Cooled Nuclear Power Plants", TECDOC-1624, IAEA, Vienna, Austria (2009).

[14] G. Yadigaroglu and J. Dreier, "Passive Advanced Light Water Reactor designs and the ALPHA program at the Paul Scherrer Institute", Kerntechnik, vol. 63, pp. 39 (1998).

[15] M. Kawakubo, H. Kikura, M. Aritomi, and T. Komeno, "Condensation heat transfer on a vertical tube under noncondensable condition", Proc. ICONE-15, Nagoya, Japan, April 22-26, 2007.

[16] S. Svetlov et al., "MIR-1200/AES-2006 Design with VVER Reactor: Evolution and Main Features", Proc. VVER-2010: Experience and Perspectives, Prague, Nov. 1-3, 2010.

[17] P. Broxtermann, D. von der Cron, and H.-J. Allelein, "Capabilities of a mechanistic model for containment condenser simulation", Proc. Jahrestagung Kerntechnik 2012, Stuttgart, Germany, May 22-24, 2012.

[18] B. Hüttermann, M. Heitsch, and B. Schwinges, "Analysis of large pools (containment cooler) (COCOSYS/CFX analysis of the PANDA building condenser experiment BC4 with large external pool)", GRS-A-2746, Cologne (1999).

[19] B. Hüttermann, "Analysis of PANDA BC3 and BC4 test with focus to the energy balance by the COCOSYS code", GRS internal report, Cologne (2001).

[20] J.C. de la Rosa, A. Escriva, L.E. Herranz, T. Cicero, and J.L. Munoz-Cobo, "Review on condensation on the containment structures”, Prog. Nucl. Energy, vol. 51, pp. 32-66 (2009).

[21] F.P. Peterson, "Diffusion Layer Modeling for Condensation With Multicomponent Noncondensable Gases", Transactions of the ASME, vol. 122 (2000).

[22] W. Kays, M. Crawford, and B. Weigand, Convective Heat and Mass Transfer, McGraw-Hill (2005).

[23] E. Bachellerie, F. Arnould, M. Auglaire, B. de Boeck, O.
Braillard, B. Eckardt, F. Ferroni, and R. Moffet, "Generic approach for designing and implementing a passive recombiner PAR-system in a nuclear power plant", $\mathrm{Nucl}$. Eng. Des., vol. 221, pp. 151-165 (2003).

[24] M. Andreani and S. Kelm, "Simulation of mixing induced by a hot PAR exhaust plume", Proc. 20th Int. Conf. Nuclear Engineering ICONE-20, Anaheim, CA, USA, July $30-$ Aug. 3, 2012.

[25] ANSYS Inc., "ANSYS CFX Solver Theory Guide - CFX Release 11.0”, Ansys Inc., Canonsburg (2006).

[26] S. Kelm, E.-A. Reinecke, W. Jahn, H.-J. Allelein, "Simulation of hydrogen mixing and mitigation by means of passive auto-catalytic recombiners", Proc. 14th Int. Top. Mtg. Nuclear Reactor Thermal Hydraulics (NURETH-14), Toronto, Ontario, Canada, Sept. 25-29, 2011.

[27] E.-A. Reinecke, A. Bentaib, S. Kelm, W. Jahn, N. Meynet, and C. Caroli, "Open issues in the applicability of recombiner experiments and modeling to reactor simulations", Prog. Nucl. Energy, vol. 52, pp. 136-147 (2010).

[28] G. Poss, T. Kanzleiter, S. Gupta, and G. Langrock, "Experimental investigation of passive autocatalytic recombiner (PAR) units under accidental scenarios", Proc. 2nd Int. Top. Mtg. Safety and Technology of Nuclear Hydrogen Production, Control and Management, San Diego, CA, USA, June 13-19, 2010.

[29] P. Drinovac, "Experimental studies on catalytic recombiners for light water reactors", PhD Dissertation RWTH Aachen University (2006).

[30] E.-A. Reinecke, J. Boehm, P. Drinovac, S. Struth, and I.M. Tragsdorf, "Numerical and experimental investigations on catalytic recombiners", Proc. 13th Int. Conf. Nuclear Engineering ICONE-13, Beijing, China, May 16-20, 2005.

[31] H.-J. Allelein et al., "State of the Art Report on Nuclear Aerosols", NEA/CSNI/R(2009)5 (2009).

[32] F. Funke, G. Langrock, T. Kanzleiter, G. Poss, K. Fischer, A. Kühnel, G. Weber, and H.-J. Allelein, "Iodine oxides in large-scale THAI tests", Nucl. Eng. Des., vol. 245, pp. 206-222 (2012)

[33] G. Bönigke, F. Ewig, H.-G. Friederichs, M. Heitsch, B. Hüttermann, U. Jendrich, S. Meier, A. Scharfe, M. Sonnenkalb, J. Rohde, and M. Tiltmann, "Contributions to elaboration of concept and measures for optimized management of beyond-design-basis accidents in German LWR power plants", GRS-A-2601, Cologne (1998). 